\title{
Prevalence of endocrine disorders in obese patients: systematic review and meta-analysis
}

\author{
L T van Hulsteijn' ${ }^{1}$, R Pasquali², F Casanueva ${ }^{3}$, M Haluzik ${ }^{4}$, S Ledoux ${ }^{5}$, M P Monteiro ${ }^{6,7}$, J Salvador ${ }^{8,9}$, F Santini ${ }^{10}$, \\ H Toplak ${ }^{11}$ and $\mathbf{O}$ M Dekkers ${ }^{12,13,14}$
}

${ }^{1}$ Department of Clinical Endocrinology and Metabolism, University Medical Centre Groningen, Groningen, The Netherlands, ${ }^{2}$ University Alma Mater Studiorum, Bologna, Italy, ${ }^{3}$ Department of Medicine, Santiago de Compostela University, Complejo Hospitalario Universitario de Santiago (CHUS), CIBER de Fisiopatologia Obesidad y Nutricion (CIBERobn), Instituto Salud Carlos III, Santiago de Compostela, Spain, ${ }^{4}$ Diabetes Centre and Centre for Experimental Medicine, Institute for Clinical and Experimental Medicine and Institute of Endocrinology, Prague, Czech Republic, ${ }^{5}$ Department of Physiology, Obesity Center, Louis Mourier Hospital (APHP), Colombes and Paris Diderot University, Paris, France, ${ }^{6}$ Endocrine, Cardiovascular \& Metabolic Research, Unit for Multidisciplinary Research in Biomedicine (UMIB), Instituto de Ciências Biomédicas Abel Salazar (ICBAS), University of Oporto, Porto, Portugal, ${ }^{7}$ Honorary Clinical Senior Lecturer and Obesity Consultant, University College of London, London, UK, ${ }^{8}$ Department of Endocrinology and Nutrition, University Clinic of Navarra, Pamplona, Spain, ${ }^{9} \mathrm{CIBEROBN}$, Instituto Carlos III, Madrid, Spain, ${ }^{10}$ Obesity and Lipodystrophy Center, University Hospital of Pisa, Pisa, Italy, ${ }^{11}$ Division of Endocrinology and Diabetology, Department of Medicine, Medical University of Graz, Graz, Austria, ${ }^{12}$ Department of Clinical Epidemiology, ${ }^{13}$ Department of Clinical Endocrinology and Metabolism, Leiden University Medical Centre, Leiden, The Netherlands, and ${ }^{14}$ Department of Clinical Epidemiology, Aarhus University Hospital, Aarhus, Denmark

Correspondence should be addressed to $L T$ van Hulsteijn Email

I.t.van.hulsteijn@umcg.nl

\begin{abstract}
Objective: The increasing prevalence of obesity is expected to promote the demand for endocrine testing. To facilitate evidence guided testing, we aimed to assess the prevalence of endocrine disorders in patients with obesity. The review was carried out as part of the Endocrine Work-up for the Obesity Guideline of the European Society of Endocrinology. Design: Systematic review and meta-analysis of the literature.

Methods: A search was performed in MEDLINE, EMBASE, Web of Science and COCHRANE Library for original articles assessing the prevalence of hypothyroidism, hypercortisolism, hypogonadism (males) or hyperandrogenism (females) in patients with obesity. Data were pooled in a random-effects logistic regression model and reported with 95\% confidence intervals $(95 \% \mathrm{Cl})$.

Results: Sixty-eight studies were included, concerning a total of 19.996 patients with obesity. The pooled prevalence of overt (newly diagnosed or already treated) and subclinical hypothyroidism was 14.0\% (95\% Cl: 9.7-18.9) and 14.6\% (95\% Cl: 9.2-20.9), respectively. Pooled prevalence of hypercortisolism was $0.9 \%$ (95\% Cl: 0.3-1.6). Pooled prevalence of hypogonadism when measuring total testosterone or free testosterone was $42.8 \%$ (95\% Cl: $37.6-48.0$ ) and $32.7 \%$ (95\% Cl: 23.1-43.0), respectively. Heterogeneity was high for all analyses.

Conclusions: The prevalence of endocrine disorders in patients with obesity is considerable, although the underlying mechanisms are complex. Given the cross-sectional design of the studies included, no formal distinction between endocrine causes and consequences of obesity could be made.
\end{abstract}

\section{Introduction}

The prevalence of obesity is rapidly increasing. According to the World Health Organization, obesity now affects (c) 2020 European Society of Endocrinology Printed in Great Britain
10-30\% of adults in European Union countries (http:// www.euro.who.int/en/health-topics/noncommunicablediseases/obesity/data-and-statistics). Although most

Published by Bioscientifica Ltd. 
cases of obesity are related to the interaction between unfavorable genes and a sedentary lifestyle and increased caloric intake, in a small proportion, secondary causes can be identified. These causes include endocrine conditions such as hypothyroidism, hypercortisolism or hypo-(males) or hyperandrogenism (females). The European Guidelines for Obesity Management in Adults therefore state that history taking should consider endocrine abnormalities and that laboratory examinations should include thyroid function for every obese patient, and an endocrine evaluation for Cushing's syndrome in case of clinical suspicion (1). The AACE/ACE Guidelines for Medical Care of Patients with Obesity state that biochemical testing for hypothyroidism or hypercortisolism is indicated if related clinical findings or symptoms are present (2).

The increasing prevalence of obesity is expected to promote the demand for endocrine testing. However, obesity and above mentioned endocrine disorders share many clinical characteristics and therefore the precise merits of biochemical testing for endocrine disorders in obese patients remain unclear. For evidenceguided testing, detailed knowledge of the prevalence of endocrine conditions in obesity is a prerequisite. The objective of this study was to perform a systematic review and meta-analysis on the prevalence of endocrine disorders (i.e. hypothyroidism, hypercortisolism or hypo- or hypergonadism) in patients with obesity. The review was carried out as part of the Endocrine Work-up for the Obesity Guideline of the European Society of Endocrinology.

\section{Methods}

\section{Eligibility criteria}

Cross-sectional studies assessing the prevalence of endocrine disorders in obese patients were eligible for inclusion. Studies including patients with obesity (BMI > 30 $\mathrm{kg} / \mathrm{m}^{2}$ ) or an increased waist circumference (determined by region- and ethnic-specific cut-off point values, see under 'Risk of bias assessment') were eligible; also studies with stratified data for the groups mentioned above were considered. The following endocrine conditions were considered: hypothyroidism, hypercortisolism, hypogonadism (males) and hyperandrogenism (females). With regard to hypothyroidism, a distinction was made between clinical (i.e. raised thyroid-stimulating hormone (TSH) and low free thyroid hormone levels) and subclinical hypothyroidism (i.e. raised TSH, normal free thyroid hormone levels) if possible. Eligible articles should present data on endocrine disorders based on biochemical tests. We relied on the choice of endocrine tests as presented in included articles and the definition of a positive test was based on cut-off values provided in included articles. The prevalence of an endocrine disorder was defined as the number of positively tested (or known treated) patients divided by the total number of tested patients.

In order to avoid the inclusion of case reports or case series, which are more prone to selection and publication bias, only studies reporting a population of ten or more patients with obesity were eligible. In case of multiple studies describing the same cohort, the study which comprised the highest number of subjects was included. Eligible studies were restricted to languages familiar to the authors (English, French, German, Dutch and Spanish). Articles that were irretrievable online were requested by contacting the authors. We also tried to contact the authors for clarification when reported data were not sufficient for accurate data extraction.

\section{Search strategy}

In May 2018, PubMed, EMBASE, Web of Science and COCHRANE were searched to identify potentially relevant studies, published from 1980 onward (Supplementary data 1 , see section on supplementary materials given at the end of this article). References of key articles were assessed for additional relevant articles.

\section{Data extraction}

All studies obtained from the search strategy were entered into reference manager software (EndNote X8, Clarivate Analytics, Philadelphia, PA) and were screened on title and abstract. Potentially relevant studies were retrieved for detailed assessment. For eligible studies, data were independently extracted by two reviewers ( $\mathrm{L} \mathrm{T} \mathrm{v} \mathrm{H}$ and $\mathrm{O} \mathrm{D})$. Disagreements between reviewers were resolved by consensus.

\section{Risk of bias assessment}

Risk of bias assessment was based on design elements that potentially bias an association between the exposed population under study (patients with obesity) and the outcome (endocrine disorders) (3):

1. Selection of patients. Inclusion of consecutive exposed patients, not selected for endocrine testing because of 
a high pre-test probability for endocrine conditions (e.g. only females with obesity and hirsutism tested for androgen excess) and exclusion of patients in whom biochemical testing could be unreliable (e.g. use of exogenous glucocorticoids in case of testing for hypercortisolism) were considered adequate.

2. Determination of exposure (endocrine dysfunction). The following biochemical tests were considered as adequate assessments of endocrine dysfunction:

- For hypothyroidism: raised thyroid-stimulating hormone (TSH) (4).

- For hypercortisolism: $\geq 2$ of the following measurements: urine free cortisol (UFC) $>$ the normal range for the assay, elevated latenight salivary cortisol (LNSC), elevated serum cortisol after 1-mg overnight dexamethasone suppression test (ODST) or after longer low-dose dexamethasone suppression test (2 mg/day for 48 h) (LDDST) (5).

- For male hypogonadism: a low total or free testosterone (TT or FT, respectively), measured on two separate days in a fasting state (6).

- For female hyperandrogenism: a high TT or FT, measured at any time during the menstrual cycle (7).

3. Ascertainment of the exposure (obesity). The WHO uses a BMI $30 \mathrm{~kg} / \mathrm{m}^{2}$ as threshold to define obese. In addition, in persons with BMI $<35 \mathrm{~kg} / \mathrm{m}^{2}$ it is advised to determine abdominal obesity, assessed by WC with region- and ethnic-specific cut-off point values, since abdominal obesity may not be captured in this BMI range but is an excellent marker for obesity-related disease risk (2). A BMI of $\geq 30 \mathrm{~kg} / \mathrm{m}^{2}$ and/or large WC as expression of abdominal obesity (definition of enlargement based on different criteria used in included articles) were therefore considered an adequate outcome determination.

Elements of risk of bias assessment were used as a marker of study quality and were used to explore potential heterogeneity.

\section{Statistical analysis}

For all studies, the number of patients tested positive for endocrine dysfunction (numerator) and the total number of patients (denominator) were used to estimate the prevalence of endocrine dysfunction. For all prevalences exact 95\% confidence intervals (95\% CI) were estimated. Meta-analysis was performed using the metaprop command in STATA (8). Given the expected clinical heterogeneity a random-effects model was performed by default. Meta-analysis was performed using an exact likelihood approach. For all analyses, indices of heterogeneity, $I^{2}$ statistics and Cochrane's Q-test, were reported. Subgroup analyses and meta-regression were used to explore potential heterogeneity. All analyses were performed with STATA 14.0 (Stata Corp).

\section{Results}

\section{Study selection}

The initial search resulted in 3819 unique records; 165 were selected for detailed assessment. After detailed assessment, 109 articles were excluded (Fig. 1). Twelve additional articles were found in references of key articles. Finally, a total of 68 studies were included in the present analysis. Two studies assessed both hypothyroidism and hypercortisolism $(9,10)$, while all other studies assessed a single endocrine condition. Except for one article which was written in Spanish (11), all articles were in English. Articles were published between 1987 and 2018. Sixty-two articles (91\%) studied a BMI defined population, 6 (9\%) studied a WC defined population.

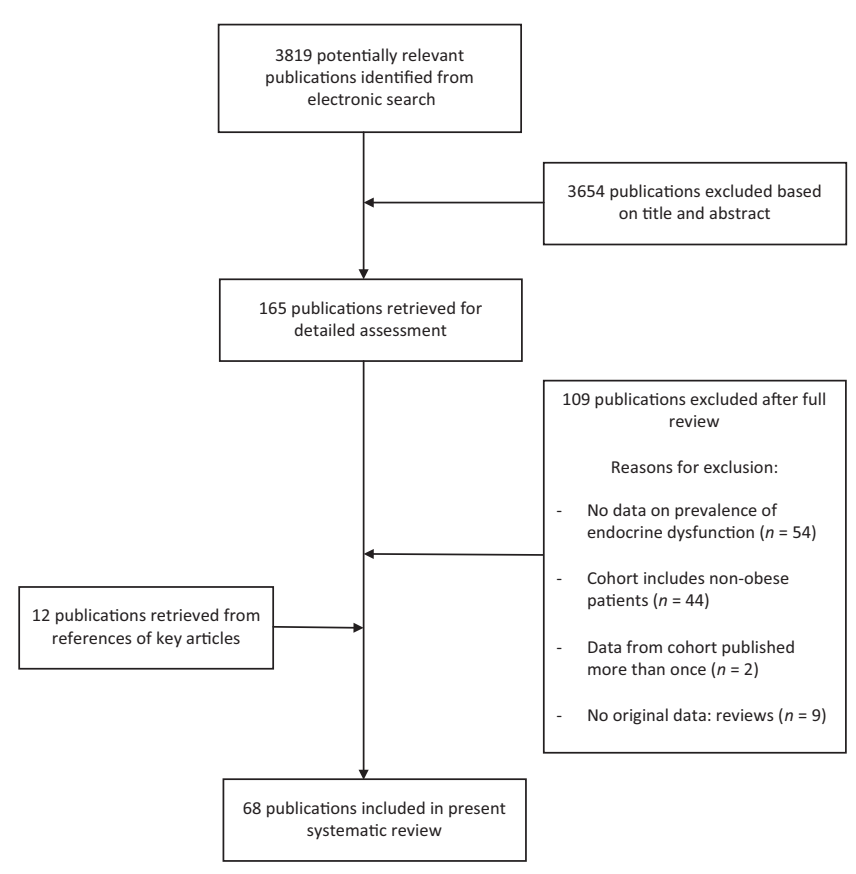

Figure 1

Study selection. 


\section{Hypothyroidism}

\section{Study characteristics}

Twenty-seven studies concerning (subclinical) hypothyroidism were included, published between 1987 and 2018. A total of 7446 patients with obesity were included, of whom at least 1288 males and 5256 females (3 studies did not differentiate gender). Mean age ranged from 35.8 to 52.7 years, mean BMI from 27.2 to $53.0 \mathrm{~kg} / \mathrm{m}^{2}$, mean WC from 95.7 to $137.5 \mathrm{~cm}$. Individual study characteristics are displayed in Supplementary data 2.

\section{Risk of bias}

Nine studies selected patients with obesity who were evaluated for bariatric surgery for inclusion $(9,10,12,13$, $14,15,16,17,18)$, one study selected patients evaluated for sleep-disordered breathing (19) and one study patients with type 2 diabetes mellitus (T2DM) (20). Four studies determined obesity by WC, the other studies by BMI. Two studies did not specify a definition of (subclinical) hypothyroidism $(15,21)$ and four studies $(14,17,18$, 22) classified patients on thyroxine substitution as hypothyroid. All other studies diagnosed (subclinical) hypothyroidism based on raised TSH levels; two studies measured TSH levels after administration of thyrotropinreleasing hormone (TRH) intravenously $(23,24)$.

\section{Prevalence of hypothyroidism}

Reported prevalence of overt (newly diagnosed or already treated) hypothyroidism ranged from 1.7 to $43.7 \%$. In studies including patients who were evaluated for bariatric surgery, that is, patients with obesity grade II or III (BMI $35.0-39.9$ or $\geq 40 \mathrm{~kg} / \mathrm{m}^{2}$ ), these numbers were $10.3-18.1 \%$ and $7.7-25 \%$, respectively. The pooled prevalence of overt hypothyroidism from a random-effects model was $14.0 \%$, 95\% CI 9.7-18.9\% (19 studies, $I^{2}=96 \%, P<0.01$ ). Studies restricted to patients undergoing bariatric surgery showed a prevalence of $12.7 \%$, 95\% CI 10.1-15.1 (six studies, $\left.I^{2}=72 \%\right)$. BMI was not positively correlated with the prevalence of overt hypothyroidism in a meta-regression; in fact, two studies with a relatively low mean BMI (34 and $37 \mathrm{~kg} / \mathrm{m}^{2}$ respectively) reported high prevalences of 32.9 and $43.7 \%$ (Figs 2 and 3 ).

Prevalence of subclinical hypothyroidism ranged from 0 to $58.3 \%$. The pooled prevalence of subclinical hypothyroidism from a random-effects model was

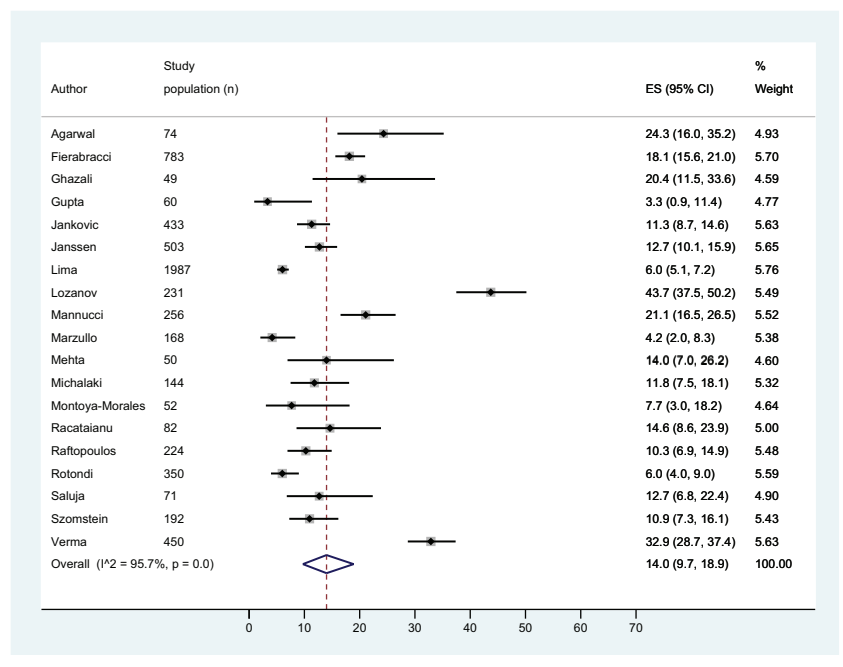

\section{Figure 2}

Prevalence of overt hypothyroidism in patients with obesity. A full colour version of this figure is available at https://doi. org/10.1530/EJE-19-0666.

14.6\%, 95\% CI 9.2-20.9\% (19 studies, $I^{2}=97 \%, P<0.01$ ). Studies restricted to patients undergoing bariatric surgery showed a prevalence of $11.9 \%, 95 \%$ CI 7.4-17.3 (five studies, $\left.I^{2}=83 \%\right)$. BMI was not positively correlated with the prevalence of subclinical hypothyroidism in a metaregression $(P=0.50)$.

\section{Hypercortisolism}

\section{Study characteristics}

Twenty-two studies concerning hypercortisolism were included, published between 1996 and 2018 (Supplementary data 3). The 22 study groups contained a total of 5819 patients: 1888 males and 3931 females, with a mean age ranging from 37.8 to 60.9 years. Mean BMI ranged from 29.8 to $51.5 \mathrm{~kg} / \mathrm{m}^{2}$.

\section{Risk of bias}

Eleven studies selected patients with concomitant T2DM for inclusion; one study patients with resistant hypertension next to obesity (25). Two studies included patients with obesity and at least two other features of Cushing's syndrome $(26,27)$. Two studies did not report exclusion criteria $(9,28)$. All studies adequately assessed obesity, one by WC (25), the others by BMI, and all used $\geq 2$ of the biochemical tests for assessment of hypercortisolism. 


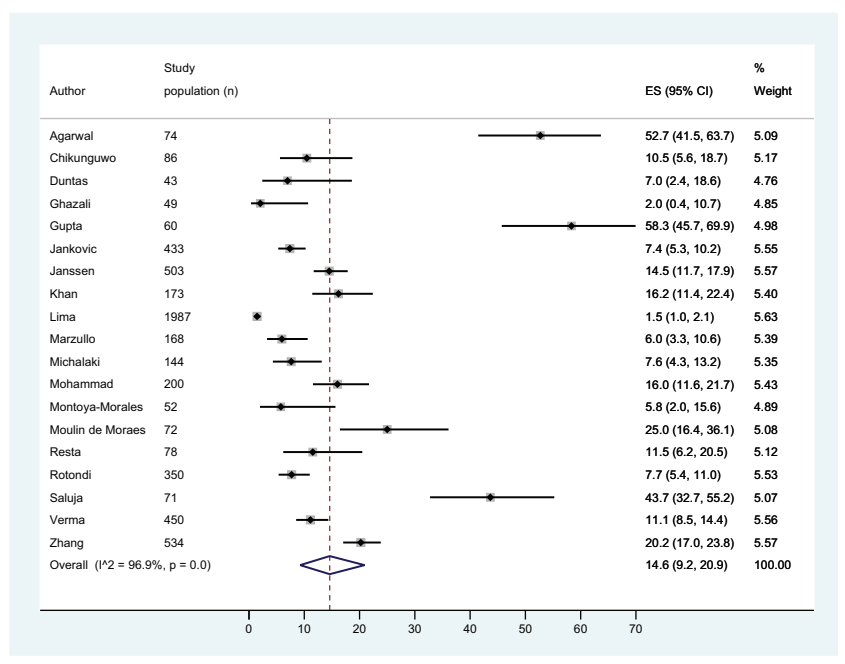

Figure 3

Prevalence of subclinical hypothyroidism in patients with obesity. A full colour version of this figure is available at https://doi.org/10.1530/EJE-19-0666.

\section{Prevalence of hypercortisolism}

Prevalence of hypercortisolism ranged from 0 to $9.3 \%$. In studies including patients with T2DM these numbers were 0 to $5.5 \%$; the study including patients with resistant hypertension reported a prevalence of $2.6 \%$ (25). The studies including patients with obesity and two other features of Cushing's syndrome both reported a prevalence of $0 \%(26,27)$. The pooled prevalence of hypercortisolism from a random-effects model was $0.9 \%, 95 \%$ CI $0.3-1.6 \%$ (22 studies, $I^{2}=79 \%, P<0.01$ ). Studies restricted to patients with T2DM did show a similar prevalence in a subgroup analysis (11 studies, prevalence $1.1 \%, 95 \%$ CI $0.3-2.1, I^{2}$ $70 \%)$. Mean BMI at the study level was not clearly related to the reported prevalence ( $P=0.69)$ (Fig. 4).

\section{Hypogonadism in males}

\section{Study characteristics}

Eighteen included studies, published from 1994 to 2016, reported on prevalence of male hypogonadism (Supplementary data 4). They comprised a total of 4546 obese male patients, with a mean age ranging from 27.9 to 61.9 years. Mean BMI ranged from 24.8 to $50.3 \mathrm{~kg} / \mathrm{m}^{2}$. Six of included studies reported data on subgroups of patients with morbid/severe obesity, defined by BMI $>40 \mathrm{~kg} / \mathrm{m}^{2}$.

\section{Risk of bias}

Seven studies selected patients with T2DM (29, 30, 31, $32,33,34,35)$ and one patients with benign prostatic

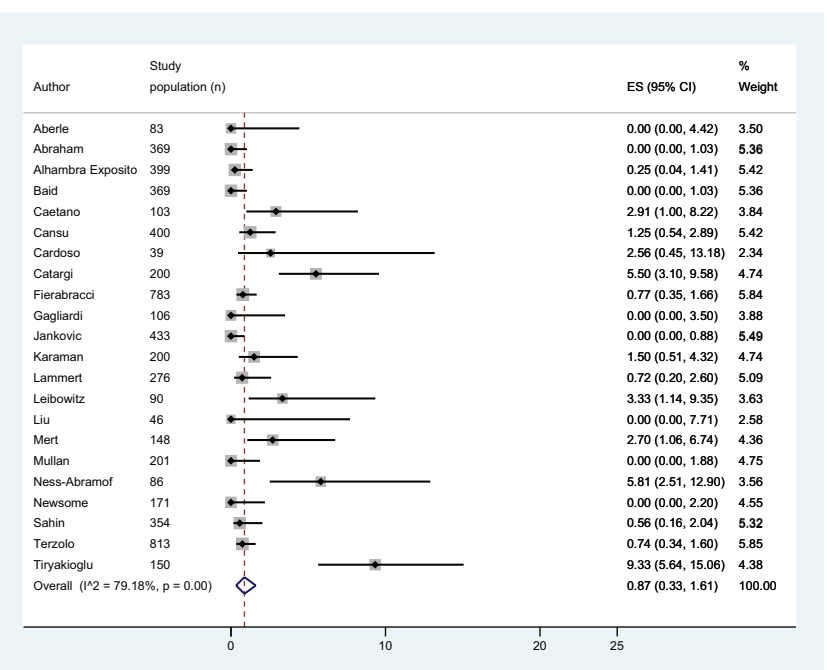

\section{Figure 4}

Prevalence of hypercortisolism in patients with obesity. A full colour version of this figure is available at https://doi. org/10.1530/EJE-19-0666.

hyperplasia (36). All studies adequately assessed exposure; one measured WC (33), all other studies BMI. All but one (33) included studies performed only one measurement of testosterone and were therefore considered at higher risk of bias. Six, five and seven studies reported on levels of TT, levels of FT or both, respectively.

\section{Prevalence of hypogonadism}

Prevalence of hypogonadism ranged from 22.9 to $78.8 \%$ and from 0 to $51.5 \%$ depending on whether low TT or low FT was used to define hypogonadism, respectively. In studies including patients with T2DM, prevalence ranged from 22.6 to $57.9 \%$. In studies describing subgroups of patients with morbid/severe obesity, prevalence ranged from 15.2 to $78.8 \%$. The pooled prevalence of hypogonadism when TT was measured was $42.8 \%$, 95\% CI $37.6-48.0 \%$ (13 studies, $I^{2}=89 \%, P<0.01$ ). The pooled prevalence of hypogonadism when FT was measured was $32.7 \%$, 95\% CI $23.1-43.0 \%$ (11 studies, $I^{2}=96 \%$, $P<0.01)$. Mean BMI at the study level was not clearly related to the reported prevalence $(P=0.16)$ (Figs 5 and 6 ).

\section{PCOS}

\section{Study characteristics}

All three included studies concerning hyperandrogenism investigated prevalence of polycystic ovary syndrome (PCOS) in a total of 2185 premenopausal obese women, 


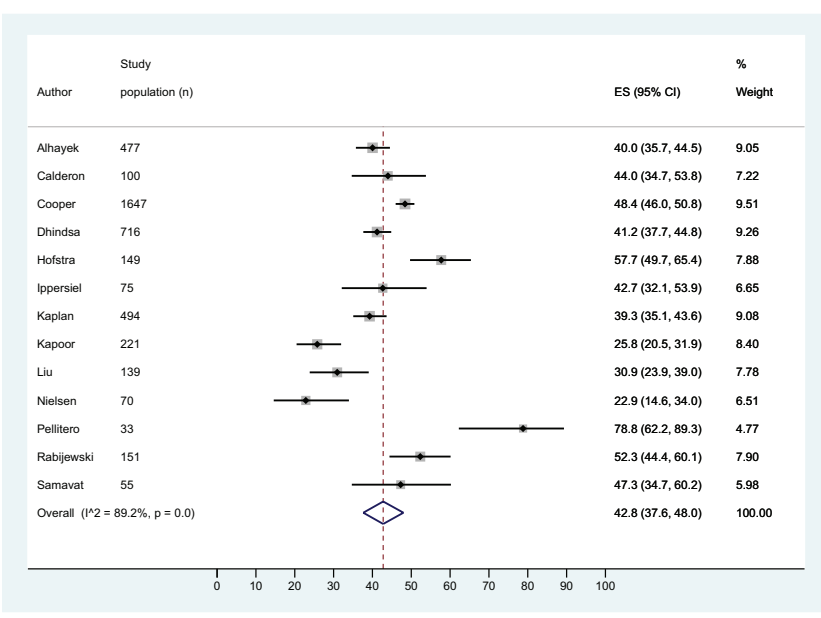

Figure 5

Prevalence of hypogonadism in patients with obesity (total testosterone). A full colour version of this figure is available at https://doi.org/10.1530/EJE-19-0666.

with a reported mean age of 37 years (Supplementary data 5). Mean BMI was not reported. Studies were published from 2006 to 2015.

\section{Risk of bias}

All studies included unselected obese premenopausal female patients with adequate assessment of exposure; obesity was defined by BMI. All three studies defined PCOS as the presence of clinical and/or biochemical hyperandrogenism (measured by FT) and ovulatory dysfunction.

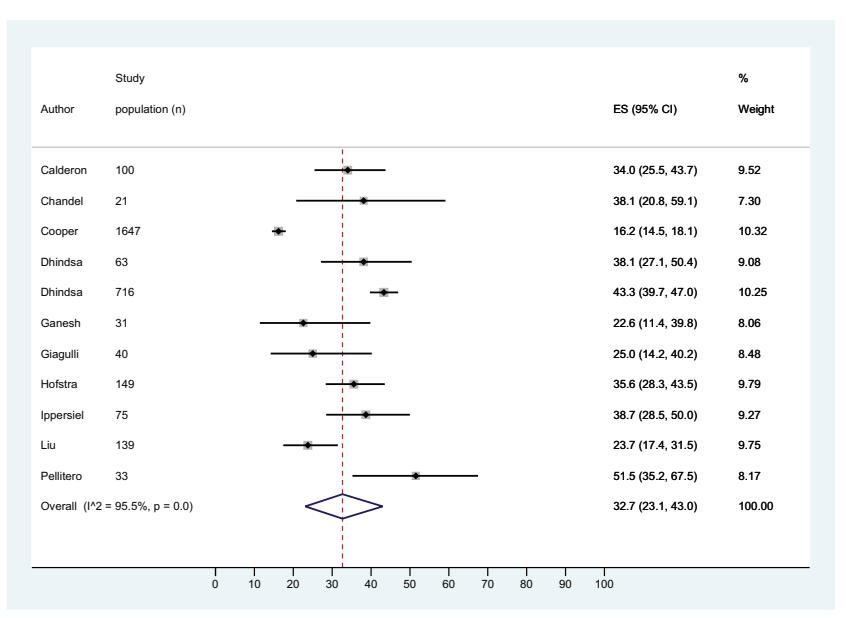

\section{Figure 6}

Prevalence of hypogonadism in patients with obesity (free testosterone). A full colour version of this figure is available at https://doi.org/10.1530/EJE-19-0666.

\section{Prevalence of hyperandrogenism}

Prevalence of PCOS ranged from 9.1 to $25 \%$, and no pooled proportion was estimated given the low number of studies.

\section{Discussion}

We performed a systematic review and meta-analysis of the prevalence of several endocrine disorders in obesity. Whereas the prevalence of hypercortisolism was low (<1\%), the prevalence of hypothyroidism and hypogonadism was considerable. However, given the cross-sectional design of the studies included, no formal distinction between endocrine causes and consequences of obesity could be made. Although heterogeneity was high for all analyses, subgroup analyses and meta-regression did not reveal clear sources of heterogeneity.

The pooled prevalence of subclinical hypothyroidism and overt (newly diagnosed or already treated) hypothyroidism in obesity were 14.6 and 14.0\%, respectively. These numbers are clearly higher than numbers in the general population, where prevalence numbers of 4.3 and $0.3 \%$ are reported for respectively subclinical hypothyroidism and overt hypothyroidism in America, and of 3.8 and $0.4 \%$ in Europe $(37,38)$. It should be noted that the male-to-female ratio in our review is 1:4 and the prevalence of thyroid disorders is known to be higher in females (4). Furthermore, the reported prevalence numbers in our review differed considerably and ranged from 0 to $58.3 \%$ (subclinical hypothyroidism) and 1.7-43.7\% (overt hypothyroidism). Likely this is due to different clinical characteristics of the various study populations. For example, high prevalence numbers of subclinical hypothyroidism were reported in studies from India $(21,39,40,41)$, where it is reported that a high prevalence of endemic goiter persists despite the implementation of iodized salt (42). Lastly, it should be noted that patients treated with levothyroxine were classified as having hypothyroidism.

The general perception is that hypothyroidism is a cause of weight gain via decreased resting energy expenditure and reduced physical activity, leading to accumulation of body fat, and a reduced capacity of excreting free water, leading to increased water content of the body (43). In line, TSH levels in the upper part of the reference range are associated with increased odds of obesity compared with TSH levels in the lower part of the reference range (44). However, the effects of hypothyroidism on weight gain are generally considered to be modest (45). In obesity, a 
positive correlation between measures of adiposity and TSH was shown, with an inverse relation to low/normal free thyroxine (FT4) (46). A possible explanation could be that the rate of thyroid hormone disposal is increased in adiposity, since turnover rate is proportional to body size. This increased disposal rate might promote activation of the hypothalamus-pituitary-thyroid axis, aimed at maintaining serum thyroid hormones within the euthyroid range (43). The net result would be biochemical subclinical hypothyroidism. This reverse relationship between obesity and hypothyroidism is further supported by the fact that several studies observed a significant decrease of TSH levels after weight loss resulting from bariatric surgery $(10,14,16)$. Importantly, treatment of hypothyroid patients with thyroxine until clinically euthyroid did not change BMI $(47,48)$.

The results of our review revealed a low prevalence of hypercortisolism in patients with obesity $(<1 \%)$. All included studies used $\geq 2$ of the biochemical tests for assessment of hypercortisolism as recommended by the Endocrine Society Guideline (5), and if positive, followed by imaging studies to determine the source of hypercortisolism. Exact prevalence numbers of hypercortisolism in the general population are not known, but the incidence of Cushing's syndrome caused by endogenous hypercortisolism is rare with an incidence of $2-3$ per million $(49,50)$.

It is important to note that half of included studies concerned T2DM patients and a recent meta-analysis showed a prevalence of $3.4 \%$ of hypercortisolism in T2DM patients (51). Interestingly, in that study adrenal/ pituitary imaging was negative in $31 \%$ of patients with documented hypercortisolism. This led the authors to the hypothesis that hypercortisolism in T2DM patients with negative imaging may reflect an underlying inflammatory component of T2DM (52) involving activation of the hypothalamus-pituitary-adrenal axis or that elevated cortisol levels occurred as a counter regulatory neuroendocrine response to hypoglycaemia (53). In our review though, imaging was negative in none of the obese patients with proven hypercortisolism (although two patients refused further investigation of the source of hypercortisolism); they were all diagnosed with a pituitary or adrenal source of hypercortisolism.

Our study revealed a relatively high prevalence of biochemical hypogonadism in obese men (pooled prevalence 33\%). The HIM (Hypogonadism in Males) study previously reported a prevalence of hypogonadism of $38.7 \%$ of men aged $\geq 45$ years presenting to primary care offices in the United States (54), with an increased risk in men with obesity (odds ratio 2.38 ). The negative correlation between testosterone and BMI in men is well established and low testosterone levels promote accumulation of total and visceral fat mass (55). It is important to consider that hypogonadism can be the cause but also the consequence of obesity (6). Several underlying mechanisms have been proposed. Firstly, elevated leptin concentrations in obese men may inhibit the production of testosterone by Leydig cells (56). Secondly, aromatase cytochrome $\mathrm{P} 450$ in adipocytes increases the conversion of testosterone to estradiol. The higher levels of estradiol cause augmentation of estrogen receptor beta expression, which downregulates glucose transporter (GLUT) 4 and therefore induce insulin resistance (57). The lower levels of adiponectin seen in obesity can also lead to increased hepatogenous glucose production and insulin resistance (58). Insulin resistance can induce decreased sex-hormone-binding globulin (SHBG) production of the liver, which in turn leads to a larger amount of TT available for conversion to estradiol in fat tissue. Because of the decrease in SHBG and the consequent altered levels of TT, the Endocrine Society recommends to measure FT instead of TT levels in obesity, unless TT concentrations are far below the lower limit of the normal range (e.g. $<150 \mathrm{ng} /$ $\mathrm{dL}$ ), in which case the probability of FT concentrations being within the normal range is low (6). Six included studies in our review assessed hypogonadism by TT. All studies reported cut-off levels for TT but none reported exact values of low TT levels. However, both studies

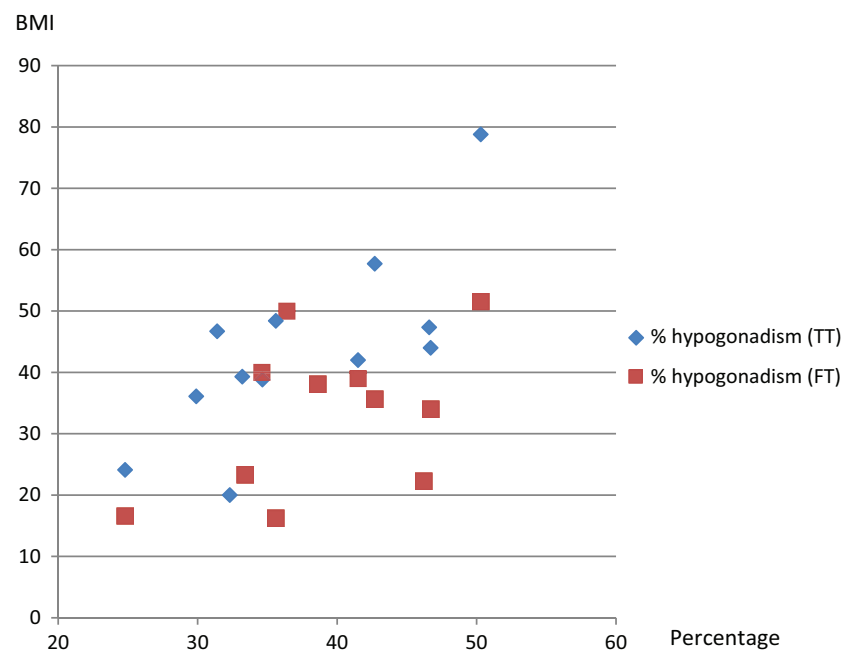

Figure 7

Prevalence of hypogonadism according to BMI. A full colour version of this figure is available at https://doi.org/10.1530/ EJE-19-0666. 
using TT and studies using FT showed the same trend of increasing prevalence of hypogonadism with increasing BMI (Fig. 7). Improvement of TT/FT levels after weight loss resulting from bariatric surgery is observed $(59,60$, 61). Conversely, several studies have shown a positive effect of testosterone replacement therapy on BMI, lean body mass and fat mass in hypogonadal men, although the effect is modest $(62,63,64,65,66)$.

Importantly, only one study met our biochemical pre-definition of hypogonadism, by using two separate measurements of testosterone (33). The reported prevalence in this study was $22.6 \%$. Since day-to-day variations in serum testosterone concentrations can be large, it is important to confirm low testosterone concentrations with repeat measurement (6).

Our literature search did not identify studies exclusively investigating prevalence of biochemical hyperandrogenism in women with obesity; only three studies investigating prevalence of PCOS were included. All three studies used the presence of clinical and/or biochemical hyperandrogenism as an essential criterion for diagnosing PCOS, but we were unable to stratify results for biochemical hyperandrogenism only. As in males, obesity in females, especially abdominal, is associated with decreased production of SHBG through insulin resistance (67). In females this is believed to increase FT fraction and therefore causes relative hyperandrogenism, amplified by the increased production rate of testosterone and nonSHBG-bound DHEA and $\Delta_{4}$-androstenedione $\left(\Delta_{4}-\mathrm{A}\right)$ seen in abdominal obesity (68). Furthermore, ovarian production of androgens is increased through the fact that insulin stimulates LH-mediated steroidogenesis in the theca cell system (69). However, visceral fat mass quantified by imaging did not differ in women with PCOS compared with BMI-matched control women $(70,71)$. This is in line with our review: prevalence of PCOS in obese women is almost similar to the general population of reproductiveaged women $(9.1-25 \%$ vs $6-20 \%$, dependent on which criteria are used to define PCOS) (7).

To conclude, the prevalence of endocrine disorders in patients with obesity is considerable, although the underlying mechanisms are complex. For the consequences for screening we refer to the Endocrine Work-up for Obesity Guideline of the European Society of Endocrinology (72).

\section{Supplementary materials}

This is linked to the online version of the paper at https://doi.org/10.1530/ EJE-19-0666.

\section{Declaration of interest}

The authors declare that there is no conflict of interest that could be perceived as prejudicing the impartiality of this study.

\section{Funding}

This research did not receive any specific grant from any funding agency in the public, commercial or not-for-profit sector.

\section{Acknowledgements}

OM D is on the editorial board of EJE. O M D was not involved in the review or editorial process for this paper, on which he is listed as an author.

\section{References}

1 Yumuk V, Tsigos C, Fried M, Schindler K, Busetto L, Micic D, Toplak H \& Obesity Management Task Force of the European Association for the Study of Obesity. European guidelines for obesity management in adults. Obesity Facts 20158 402-424. (https://doi. org/10.1159/000442721)

2 Garvey WT, Mechanick JI, Brett EM, Garber AJ, Hurley DL, Jastreboff AM, Nadolsky K, Pessah-Pollack R, Plodkowski R \& Reviewers of the AACE/ACE Obesity Clinical Practice Guidelines. American Association of Clinical Endocrinologists and American College of Endocrinology comprehensive clinical practice guidelines for medical care of patients with obesity. Endocrine Practice 201622 1-203. (https://doi.org/10.4158/EP161365.GL)

3 Dekkers OM, Vandenbroucke JP, Cevallos M, Renehan AG, Altman DG \& Egger M. COSMOS-E: guidance on conducting systematic reviews and meta-analyses of observational studies of etiology. PLoS Medicine 201916 e1002742. (https://doi.org/10.1371/ journal.pmed.1002742)

4 Garber JR, Cobin RH, Gharib H, Hennessey JV, Klein I, Mechanick JI, Pessah-Pollack R, Singer PA, Woeber KA \& American Association of Clinical Endocrinologists and American Thyroid Association Taskforce on Hypothyroidism in Adults. Clinical practice guidelines for hypothyroidism in adults: cosponsored by the American Association of Clinical Endocrinologists and the American Thyroid Association. Endocrine Practice 201218 988-1028. (https://doi. org/10.4158/EP12280.GL)

5 Nieman LK, Biller BMK, Findling JW, Newell-Price J, Savage MO, Stewart PM \& Montori VM. The diagnosis of Cushing's syndrome: an Endocrine Society clinical practice guideline. Journal of Clinical Endocrinology and Metabolism 200893 1526-1540. (https://doi. org/10.1210/jc.2008-0125)

6 Bhasin S, Brito JP, Cunningham GR, Hayes FJ, Hodis HN, Matsumoto AM, Snyder PJ, Swerdloff RS, Wu FC \& Yialamas MA. Testosterone therapy in men with hypogonadism: an Endocrine Society clinical practice guideline. Journal of Clinical Endocrinology and Metabolism 2018103 1715-1744. (https://doi.org/10.1210/jc.201800229)

7 Conway G, Dewailly D, Diamanti-Kandarakis E, Escobar-Morreale HF, Franks S, Gambineri A, Kelestimur F, Macut D, Micic D, Pasquali R et al. The polycystic ovary syndrome: a position statement from the European Society of Endocrinology. European Journal of Endocrinology 2014171 P1-P29. (https://doi.org/10.1530/EJE-14-0253)

8 Nyaga VN, Arbyn M \& Aerts M. Metaprop: a Stata command to perform meta-analysis of binomial data. Archives of Public Health 201472 39. (https://doi.org/10.1186/2049-3258-72-39)

9 Fierabracci P, Pinchera A, Martinelli S, Scartabelli G, Salvetti G, Giannetti M, Pucci A, Galli G, Ricco I, Querci G et al. Prevalence of endocrine diseases in morbidly obese patients scheduled for bariatric 
surgery: beyond diabetes. Obesity Surgery 201121 54-60. (https://doi org/10.1007/s11695-010-0297-6)

10 Janković D, Wolf P, Anderwald CH, Winhofer Y, PromintzerSchifferl M, Hofer A, Langer F, Prager G, Ludvik B, Gessl A et al. Prevalence of endocrine disorders in morbidly obese patients and the effects of bariatric surgery on endocrine and metabolic parameters. Obesity Surgery 201222 62-69. (https://doi.org/10.1007/s11695-0110545-4)

11 Alhambra Expósito MR, Tenorio Jiménez C, Molina Puerta MJ, Manzano García G, Prior Sánchez I, Muñoz Jiménez C \& Gálvez Moreno MÁ. Screening for Cushing's syndrome in obese patients; is it really necessary? Nutricion Hospitalaria 201429 1020-1023. (https://doi.org/10.3305/nh.2014.29.5.7256)

12 Chikunguwo S, Brethauer S, Nirujogi V, Pitt T, Udomsawaengsup S, Chand B \& Schauer P. Influence of obesity and surgical weight loss on thyroid hormone levels. Surgery for Obesity and Related Diseases 20073 631-635; discussion 635. (https://doi.org/10.1016/j. soard.2007.07.011)

13 Gómez-Zamudio JH, Mendoza-Zubieta V, Ferreira-Hermosillo A, Molina-Ayala MA, Valladares-Sálgado A, Suárez-Sánchez F, de Jesús Peralta-Romero J \& Cruz M. High thyroid-stimulating hormone levels increase proinflammatory and cardiovascular markers in patients with extreme obesity. Archives of Medical Research 201647 476-482. (https://doi.org/10.1016/j.arcmed.2016.10.007)

14 Janssen IM, Homan J, Schijns W, Betzel B, Aarts EO, Berends FJ \& de Boer H. Subclinical hypothyroidism and its relation to obesity in patients before and after Roux-en-Y gastric bypass. Surgery for Obesity and Related Diseases 201511 1257-1263. (https://doi.org/10.1016/j. soard.2015.02.021)

15 Michalaki MA, Vagenakis AG, Leonardou AS, Argentou MN, Habeos IG, Makri MG, Psyrogiannis AI, Kalfarentzos FE \& Kyriazopoulou VE. Thyroid function in humans with morbid obesity. Thyroid 200616 73-78. (https://doi.org/10.1089/thy.2006.16.73)

16 Moulin de Moraes CM, Mancini MC, de Melo ME, Figueiredo DA, Villares SM, Rascovski A, Zilberstein B \& Halpern A. Prevalence of subclinical hypothyroidism in a morbidly obese population and improvement after weight loss induced by Roux-en-Y gastric bypass. Obesity Surgery 200515 1287-1291. (https://doi org/10.1381/096089205774512537)

17 Raftopoulos Y, Gagné DJ, Papasavas P, Hayetian F, Maurer J, Bononi P \& Caushaj PF. Improvement of hypothyroidism after laparoscopic Roux-en-Y gastric bypass for morbid obesity. Obesity Surgery 200414 509-513. (https://doi.org/10.1381/096089204323013514)

18 Szomstein S, Avital S, Brasesco O, Mehran A, Cabral JM \& Rosenthal R. Laparoscopic gastric bypass in patients on thyroid replacement therapy for subnormal thyroid function - prevalence and short-term outcome. Obesity Surgery 200414 95-97. (https://doi. org/10.1381/096089204772787365)

19 Resta O, Pannacciulli N, Di Gioia G, Stefàno A, Barbaro MP \& De Pergola G. High prevalence of previously unknown subclinical hypothyroidism in obese patients referred to a sleep clinic for sleep disordered breathing. Nutrition, Metabolism, and Cardiovascular Diseases 200414 248-253. (https://doi.org/10.1016/S09394753(04)80051-6)

20 Ghazali SM \& Abbiyesuku FM. Thyroid dysfunction in type 2 diabetics seen at the University College Hospital, Ibadan, Nigeria. Nigerian Journal of Physiological Sciences 201025 173-179.

21 Saluja M, Pyasarbadi P, Jelia S, Chittora S, Swami Y \& Vimlani H. Study of thyroid dysfunction in metabolic syndrome and associations with its components. Current Medicine Research and Practice 20188 3-7. (https://doi.org/10.1016/j.cmrp.2017.11.010)

22 Rotondi M, Leporati P, La Manna A, Pirali B, Mondello T, Fonte R, Magri F \& Chiovato L. Raised serum TSH levels in patients with morbid obesity: is it enough to diagnose subclinical hypothyroidism? European Journal of Endocrinology 2009160 403-408. (https://doi. org/10.1530/EJE-08-0734)
23 Duntas L, Hauner H, Rosenthal J \& Pfeiffer EF. Thyrotropin releasing hormone (TRH) immunoreactivity and thyroid function in obesity. International Journal of Obesity $1991 \mathbf{1 5} 83-87$.

24 Lima N, Cavaliere H \& Medeiros-Neto GA. A retrospective study of thyroid autoimmunity and hypothyroidism in a random obese population. In Thyroid Autoimmunity, pp 591-593. Eds A Pinchera, SH Ingbar, JM McKenzie \& GF Fenzi. Boston, MA: Springer, 1987.

25 Cardoso EM, Arregger AL, Monardes G \& Contreras LN. An accurate, non-invasive approach to diagnose Cushing's syndrome in at-risk populations. Steroids $2013 \mathbf{7 8}$ 476-482. (https://doi.org/10.1016/j. steroids.2013.02.005)

26 Abraham SB, Rubino D, Sinaii N, Ramsey S \& Nieman LK. Cortisol, obesity, and the metabolic syndrome: a cross-sectional study of obese subjects and review of the literature. Obesity 201321 E105-E117. (https://doi.org/10.1002/oby.20083)

27 Baid SK, Rubino D, Sinaii N, Ramsey S, Frank A \& Nieman LK. Specificity of screening tests for Cushing's syndrome in an overweight and obese population. Journal of Clinical Endocrinology and Metabolism 200994 3857-3864. (https://doi.org/10.1210/ jc.2008-2766)

28 Leibowitz G, Tsur A, Chayen SD, Salameh M, Raz I, Cerasi E \& Gross DJ. Pre-clinical Cushing's syndrome: an unexpected frequent cause of poor glycaemic control in obese diabetic patients. Clinical Endocrinology 199644 717-722. (https://doi.org/10.1046/j.13652265.1996.737558.x)

29 Alhayek AA, Khader YS, Jafal S, Khawaja N \& Ajlouni K. Hypogonadism among Jordanian men with type 2 diabetes: prevalence and associated factor. International Journal of Diabetes Mellitus 20153 31-36. (https://doi.org/10.1016/j.ijdm.2011.01.003)

30 Chandel A, Dhindsa S, Topiwala S, Chaudhuri A \& Dandona P. Testosterone concentration in young patients with diabetes. Diabetes Care 200831 2013-2017. (https://doi.org/10.2337/dc08-0851)

31 Dhindsa S, Prabhakar S, Sethi M, Bandyopadhyay A, Chaudhuri A $\&$ Dandona P. Frequent occurrence of hypogonadotropic hypogonadism in type 2 diabetes. Journal of Clinical Endocrinology and Metabolism 200489 5462-5468. (https://doi.org/10.1210/jc.20040804)

32 Dhindsa S, Miller MG, McWhirter CL, Mager DE, Ghanim H, Chaudhuri A \& Dandona P. Testosterone concentrations in diabetic and nondiabetic obese men. Diabetes Care 201033 1186-1192. (https://doi.org/10.2337/dc09-1649)

33 Ganesh HK, Vijaya Sarathi HA, George J, Shivane VK, Bandgar T, Menon PS \& Shah NS. Prevalence of hypogonadism in patients with type 2 diabetes mellitus in an Asian Indian study group. Endocrine Practice 200915 513-520. (https://doi.org/10.4158/EP09035.ORR)

34 Kapoor D, Aldred H, Clark S, Channer KS \& Jones TH. Clinical and biochemical assessment of hypogonadism in men with type 2 diabetes: correlations with bioavailable testosterone and visceral adiposity. Diabetes Care 200730 911-917. (https://doi.org/10.2337/ dc06-1426)

35 Rabijewski M, Papierska L, Zgliczyński W \& Piątkiewicz P. The incidence of hypogonadotropic hypogonadism in type 2 diabetic men in Polish population. BioMed Research International 20132013 767496. (https://doi.org/10.1155/2013/767496)

36 Kaplan SA, Lee JY, O'Neill EA, Meehan AG \& Kusek JW. Prevalence of low testosterone and its relationship to body mass index in older men with lower urinary tract symptoms associated with benign prostatic hyperplasia. Aging Male 201316 169-172. (https://doi.org/1 $0.3109 / 13685538.2013 .844786)$

37 Hollowell JG, Staehling NW, Flanders WD, Hannon WH, Gunter EW, Spencer CA \& Braverman LE. Serum TSH, T(4), and thyroid antibodies in the United States population (1988 to 1994): National Health and Nutrition Examination Survey (NHANES III). Journal of Clinical Endocrinology and Metabolism 200287 489-499.

38 Gamendia Madariaga A, Santos Palacios S, Guillen-Grima F \& Galofre JC. The incidence and prevalence of thyroid dysfunction 
in Europe: a meta-analysis. Journal of Clinical Endocrinology and Metabolism 201499 923-931. (https://doi.org/10.1210/jc.2013-2409)

39 Agarwal G, Sudhakar MK, Singh M, Senthil N \& Rajendran A. The prevalence of thyroid dysfunction among South Indian women with Metabolic Syndrome. Journal of Clinical and Diagnostic Research 2011 5 213-216.

40 Gupta H, Sheth SP \& Vaishnav B. Association of subclinical hypothyroidism with metabolic syndrome: a cross-sectional study from Western India. Asian Journal of Pharmaceutical and Clinical Research $20169265-269$

41 Verma A, Jayaraman M, Kumar HKVS \& Modi KD. Hypothyroidism and obesity, cause of effect? Saudi Medical Journal 200829 1135-1138.

42 Marwaha RK, Tandon N, Gupta N, Karak AK, Verma K \& Kochupillai N. Residual goitre in the postiodization phase: iodine status, thiocyanate exposure and autoimmunity. Clinical Endocrinology 200359 672-681. (https://doi.org/10.1046/j.13652265.2003.01895.x)

43 Santini F, Marzullo P, Rotondi M, Ceccarini G, Pagano L, Ippolito S, Chiovato L \& Biondi B. Mechanisms in endocrinology: the crosstalk between thyroid gland and adipose tissue: signal integration in health and disease. European Journal of Endocrinology 2014171 R137-R152. (https://doi.org/10.1530/EJE-14-0067)

44 Taylor PN, Razvi S, Pearce SH \& Dayan CM. Clinical review: a review of the clinical consequences of variation in thyroid function within the reference range. Journal of Clinical Endocrinology and Metabolism 201398 3562-3571. (https://doi.org/10.1210/jc.2013-1315)

45 Portmann L \& Giusti V. Obesity and hypothyroidism: myth or reality? Revue Medicale Suisse 20073 859-862.

46 de Moura Souza A \& Sichieri R. Association between serum TSH concentration within the normal range and adiposity. European Journal of Endocrinology 2011165 11-15. (https://doi.org/10.1530/EJE-11-0261)

47 Pinkney JH, Goodrick SJ, Katz JR, Johnson AB, Lightman SL, Coppack SW, Medbak S \& Mohamed-Ali V. Thyroid and sympathetic influences on plasma leptin in hypothyroidism and hyperthyroidism. International Journal of Obesity and Related Metabolic Disorders 200024 (Supplement 2) S165-S166. (https://doi. org/10.1038/sj.ijo.0801316)

48 Lee SY, Braverman LE \& Pearce EN. Changes in body weight after treatment of primary hypothyroidism with levothyroxine. Endocrine Practice 201420 1122-1128. (https://doi.org/10.4158/EP14072.OR)

49 Steffensen C, Bak AM, Rubeck KZ \& Jorgensen JOL. Epidemiology of Cushing's syndrome. Neuroendocrinology 201092 (Supplement 1) 1-5. (https://doi.org/10.1159/000314297)

50 Lindholm J, Juul S, Jorgensen JOL, Astrup J, Bjerre P, FeldtRasmussen U, Hagen C, Jorgensen J, Kosteljanetz M, Kristensen L et al. Incidence and late prognosis of Cushing's syndrome: a populationbased study. Journal of Clinical Endocrinology and Metabolism 200186 117-123. (https://doi.org/10.1210/jcem.86.1.7093)

51 Steffensen C, Pereira AM, Dekkers OM \& Jørgensen JO. Diagnosis of endocrine disease: prevalence of hypercortisolism in type 2 diabetes patients: a systematic review and meta-analysis. European Journal of Endocrinology 2016175 R247-R253. (https://doi.org/10.1530/EJE-160434)

52 Donath MY \& Shoelson SE. Type 2 diabetes as an inflammatory disease. Nature Reviews: Immunology 201111 98-107. (https://doi. org/10.1038/nri2925)

53 Davis SN, Mann S, Briscoe VJ, Ertl AC \& Tate DB. Effects of intensive therapy and antecedent hypoglycemia on counterregulatory responses to hypoglycemia in type 2 diabetes. Diabetes 200958 701-709. (https://doi.org/10.2337/db08-1230)

54 Mulligan T, Frick MF, Zuraw QC, Stemhagen A \& McWhirter C. Prevalence of hypogonadism in males aged at least 45 years: the HIM study. International Journal of Clinical Practice 200660 762-769. (https://doi.org/10.1111/j.1742-1241.2006.00992.x)

55 Ng Tang Fui M, Hoermann R, Cheung AS, Gianatti EJ, Zajac JD \& Grossmann M. Obesity and age as dominant correlates of low testosterone in men irrespective of diabetes status. Andrology 20131 906-912. (https://doi.org/10.1111/j.2047-2927.2013.00124.x)

56 Baldelli R, Dieguez C \& Casanueva FF. The role of leptin in reproduction: experimental and clinical aspects. Annals of Medicine 200234 5-18. (https://doi.org/10.1080/078538902317338599)

57 Cohen PG. Obesity in men: the hypogonadal-estrogen receptor relationship and its effect on glucose homeostasis. Medical Hypotheses 200870 358-360. (https://doi.org/10.1016/j.mehy.2007.05.020)

58 Michalakis K, Mintziori G, Kaprara A, Tarlatzis BC \& Goulis DG. The complex interaction between obesity, metabolic syndrome and reproductive axis: a narrative review. Metabolism: Clinical and Experimental 201362 457-478. (https://doi.org/10.1016/j. metabol.2012.08.012)

59 Hammoud A, Gibson M, Hunt SC, Adams TD, Carrell DT, Kolotkin RL \& Meikle AW. Effect of Roux-en-Y gastric bypass surgery on the sex steroids and quality of life in obese men. Journal of Clinical Endocrinology and Metabolism 200994 1329-1332. (https://doi. org/10.1210/jc.2008-1598)

60 Pellitero S, Olaizola I, Alastrue A, Martínez E, Granada ML, Balibrea JM, Moreno P, Serra A, Navarro-Díaz M, Romero R et al. Hypogonadotropic hypogonadism in morbidly obese males is reversed after bariatric surgery. Obesity Surgery 201222 1835-1842. (https://doi.org/10.1007/s11695-012-0734-9)

61 Samavat J, Facchiano E, Lucchese M, Forti G, Mannucci E, Maggi M $\&$ Luconi M. Hypogonadism as an additional indication for bariatric surgery in male morbidobesity? European Journal of Endocrinology 2014171 555-560. (https://doi.org/10.1530/EJE-14-0596)

62 Wang C, Swerdloff RS, Iranmanesh A, Dobs A, Snyder PJ, Cunningham G, Matsumoto AM, Weber T, Berman N \& Testosterone Gel Study Group. Transdermal testosterone gel improves sexual function, mood, muscle strength, and body composition parameters in hypogonadal men. Journal of Clinical Endocrinology and Metabolism 200085 2839-2853. (https://doi.org/10.1210/jcem.85.8.6747)

63 Isidori AM, Giannetta E, Greco EA, Gianfrilli D, Bonifacio V, Isidori A, Lenzi A \& Fabbri A. Effects of testosterone on body composition, bone metabolism and serum lipid profile in middleaged men: a meta-analysis. Clinical Endocrinology 200563 280-293. (https://doi.org/10.1111/j.1365-2265.2005.02339.x)

64 Srinivas-Shankar U, Roberts SA, Connolly MJ, O'Connell MD, Adams JE, Oldham JA \& Wu FC. Effects of testosterone on muscle strength, physical function, body composition, and quality of life in intermediate-frail and frail elderly men: a randomized, doubleblind, placebo-controlled study. Journal of Clinical Endocrinology and Metabolism 201095 639-650. (https://doi.org/10.1210/jc.2009-1251)

65 Behre HM, Tammela TL, Arver S, Tolrá JR, Bonifacio V, Lamche M, Kelly J, Hiemeyer F, European Testogel® Study Team, Giltay EJ et al. A randomized, double-blind, placebo-controlled trial of testosterone gel on body composition and health-related quality-of-life in men with hypogonadal to low-normal levels of serum testosterone and symptoms of androgen deficiency over 6 months with 12 months open-label follow-up. Aging Male 201215 198-207. (https://doi.org/1 $0.3109 / 13685538.2012 .699562)$

66 Pexman-Fieth C, Behre HM, Morales A, Kan-Dobrosky N \& Miller MG. A 6-month observational study of energy, sexual desire, and body proportions in hypogonadal men treated with a testosterone 1\% gel. Aging Male 201417 1-11. (https://doi.org/10.31 09/13685538.2013.858113)

67 Ehrmann DA. Polycystic ovary syndrome. New England Journal of Medicine 2005352 1223-1236. (https://doi.org/10.1056/ NEJMra041536)

68 Pasquali R, Gambineri A \& Pagotto U. The impact of obesity on reproduction in women with polycystic ovary syndrome. BJOG 2006 113 1148-1159. (https://doi.org/10.1111/j.1471-0528.2006.00990.x)

69 Bergh C, Carlsson B, Olsson JH, Selleskog U \& Hillensjö T. Regulation of androgen production in cultured human thecal cells by insulinlike growth factor I and insulin. Fertility and Sterility $1993 \mathbf{5 9}$ 323-331. (https://doi.org/10.1016/s0015-0282(16)55675-1) 
70 Barber TM, Golding SJ, Alvey C, Wass JA, Karpe F, Franks S \& McCarthy MI. Global adiposity rather than abnormal regional fat distribution characterizes women with polycystic ovary syndrome. Journal of Clinical Endocrinology and Metabolism 200893 999-1004. (https://doi.org/10.1210/jc.2007-2117)

71 Mannerås-Holm L, Leonhardt $\mathrm{H}$, Kullberg J, Jennische E, Odén A, Holm G, Hellström M, Lönn L, Olivecrona G, Stener-Victorin E et al. Adipose tissue has aberrant morphology and function in PCOS: enlarged adipocytes and low serum adiponectin, but not circulating sex steroids, are strongly associated with insulin resistance. Journal of Clinical Endocrinology and Metabolism 201196 E304-E311. (https:// doi.org/10.1210/jc.2010-1290)

72 Pasquali R, Casanueva F, Haluzik M, van Hulsteijn L, Ledoux S, Monteiro MP, Salvador J, Santini F, Toplak H \& Dekkers OM.

ESE guideline: endocrine work-up in obesity. European Journal of Endocrinology 2020182 G1-G32. (https://doi.org/10.1530/EJE-19-0893)

Received 28 August 2019

Revised version received 17 October 2019

Accepted 24 October 2019 